\title{
Fibroblast growth factor- 23 is associated with imaging markers of diabetic cardiomyopathy and anti-diabetic therapeutics
}

\author{
Martin H. Sørensen ${ }^{1,2^{*}}$ (D), Annemie S. Bojer ${ }^{1,2}$, Niklas R. Jørgensen ${ }^{3,7}$, David A. Broadbent ${ }^{4,5}$, Sven Plein ${ }^{5}$, \\ Per L. Madsen ${ }^{6,7}$ and Peter Gæde ${ }^{1,2}$
}

\begin{abstract}
Background: The biomarker fibroblast growth factor-23 (FGF-23) has been associated with increased cardiovascular morbidity and mortality in both patients with and without type 2 diabetes. The aim of this study was to evaluate the relationship between FGF-23 and cardiac structure, function and perfusion in patients with type 2 diabetes and normal or mildly impaired kidney function. Furthermore, to investigate the association between FGF-23, anti-diabetes therapy and the classic complications and risk factors associated with type 2 diabetes.
\end{abstract}

Methods: In this cross-sectional study, 246 patients with type 2 diabetes underwent echocardiography and advanced cardiac magnetic resonance imaging to assess left ventricular (LV) structure and function. In addition, myocardial blood flow (MBF) during rest and pharmacological stress (adenosine $140 \mu \mathrm{g} / \mathrm{kg} / \mathrm{min}$ ) were evaluated in 183 of the patients. Patients with eGFR $<60 \mathrm{ml} / \mathrm{min} / 1.73 \mathrm{~m}^{2}$ were excluded.

Results: Median (Q1-Q3) FGF-23 was 74 (58-91) ng/L. Patients with FGF-23 above the median had lower MBF during stress $(2.3 \pm 0.9$ vs. $2.7 \pm 0.9 \mathrm{ml} / \mathrm{min} / \mathrm{g}, P=0.001)$ and lower overall myocardial perfusion reserve (MPR) $(2.7 \pm 0.8 \mathrm{vs}$. $3.3 \pm 1.1, P<0.001)$. LV mass ( $143 \pm 40$ vs. $138 \pm 36 \mathrm{~g}, \mathrm{P}=0.04)$ and $E / \mathrm{e}^{*}(8.5 \pm 3.2 \mathrm{vs} .7 .6 \pm 2.7, \mathrm{P}=0.04)$ were higher in patients with FGF-23 above the median. In a linear model adjusted for age, sex, eGFR and hypertension, increasing FGF-23 was associated with decreased MPR $\left(P<0.01, R^{2}=0.11\right)$ and increased $E / e^{*}\left(P<0.01, R^{2}=0.07\right)$. FGF-23 was lower in patients receiving glucagon like peptide-1 (GLP-1) analogues (71 (57-86) vs. $80(60-98) \mathrm{ng} / \mathrm{L}, \mathrm{P}=0.01$ ) than in those who did not receive GLP-1 analogues.

Conclusions: In patients with type 2 diabetes and normal or mildly impaired kidney function, increased levels of FGF-23 are associated with impaired cardiac diastolic function and decreased MPR, caused by a decrease in maximal $\mathrm{MBF}$ during stress. Use of GLP-1 analogues is associated with decreased levels of FGF-23.

Clinical trial registration https://www.clinicaltrials.gov. Unique identifier: NCT02684331. Date of registration: February 18,2016

Keywords: Type 2 diabetes, Myocardial perfusion, Fibroblast growth factor-23, Diabetic cardiomyopathy, Cardiac magnetic resonance imaging

${ }^{*}$ Correspondence: mahso@regionsjaelland.dk

${ }^{1}$ Department of Cardiology and Endocrinology, Slagelse Hospital, Ingemannsvej 32, 4200 Slagelse, Region Zealand, Denmark

Full list of author information is available at the end of the article

\section{Background}

The link between type 2 diabetes and cardiovascular disease is well established. In patients with type 2 diabetes, the risk of developing coronary artery disease (CAD), heart failure, and cardiovascular death is significantly increased compared to those without type 2 diabetes

(c) The Author(s) 2020. This article is licensed under a Creative Commons Attribution 4.0 International License, which permits use, sharing, adaptation, distribution and reproduction in any medium or format, as long as you give appropriate credit to the original author(s) and the source, provide a link to the Creative Commons licence, and indicate if changes were made. The images or other third party material in this article are included in the article's Creative Commons licence, unless indicated otherwise in a credit line to the material. If material is not included in the article's Creative Commons licence and your intended use is not permitted by statutory regulation or exceeds the permitted use, you will need to obtain permission directly from the copyright holder. To view a copy of this licence, visit http://creativecommons.org/licenses/by/4.0/. The Creative Commons Public Domain Dedication waiver (http://creativecommons.org/publicdomain/zero/1.0/) applies to the data made available in this article, unless otherwise stated in a credit line to the data. 
$[1,2]$. The mechanism and pathophysiology behind this increased risk of cardiovascular disease have been of interest for researchers for decades; yet, no conclusive results or methods for identifying those at increased risk have been discovered so far. Fibroblast growth factor-23 (FGF-23) is a hormone secreted from osteocytes and plays an important role in vitamin $\mathrm{D}$ and phosphate homeostasis [3]. When renal function declines in patients with chronic kidney disease the concentration of circulating FGF-23 is increased in response to persistent hyperphosphatemia [4]; however, increased levels of FGF-23 have also been associated with an increased risk of developing heart failure, cardiovascular disease, and cardiovascular death independent of renal function and other cardiovascular risk factors $[5,6]$. In patients with combined type 2 diabetes and CAD, FGF-23 independently predicts adverse cardiovascular outcome [7] and, additionally, elevated FGF-23 concentrations following acute coronary syndrome are associated with an increased risk of $\mathrm{CV}$ death and hospitalization due to heart failure [8]. Furthermore, a recent study of patients with type 2 diabetes and normal or mildly impaired kidney function showed that FGF-23 was associated with an increased risk of both major adverse cardiovascular events and all-cause mortality [9]. Given the evidence of a relationship between levels of FGF-23 and cardiovascular outcome, we hypothesized that FGF-23 may be associated with structural and functional changes in the heart. Previous research on this topic is scarce and, to our knowledge, it has never been investigated using advanced imaging techniques such as cardiac magnetic resonance imaging (CMR), a technique that allows for detailed and accurate assessment of cardiac structure, function and perfusion. In this study, we investigated the association between FGF-23 and cardiac remodeling and subclinical cardiac disease measured by CMR in a large cohort of patients with type 2 diabetes and normal or mildly impaired kidney function. In addition, we investigated the relationship between FGF-23, anti-diabetes therapy and the classic complications and risk factors known to be associated with type 2 diabetes.

\section{Methods}

The study was conducted at the Department of Cardiology and Endocrinology, Slagelse Hospital, and at the Department of Radiology, Næstved Hospital, Denmark. It was approved by the local ethics committee, Region Zealand, Denmark (SJ-490) and complied with the declaration of Helsinki. Detailed information about the study design and study cohort has previously been published [10]. In short, this study is part of a cross-sectional survey of patients with type 2 diabetes. Patients were recruited from the outpatient clinic at the Department of
Endocrinology at Næstved/Slagelse/Ringsted (NSR) Hospitals, in the period from February 2016 to January 2019. Patients aged 18-80 years and with type 2 diabetes for at least 3 months were eligible to participate. Patients with permanent or persistent atrial fibrillation, contraindications to CMR or an eGFR $<30 \mathrm{ml} / \mathrm{min} / 1.73 \mathrm{~m}^{2}$ (contraindication to the contrast agent gadolinium) were excluded from the original study cohort. In patients with chronic kidney disease, FGF-23 can rise to very high levels. To reduce the risk of confounding, we further excluded patients with $\mathrm{eGFR}<60 \mathrm{ml} / \mathrm{min} / 1.73 \mathrm{~m}^{2}$ in this study, and only examined those with normal or mildly impaired kidney function. Prior to participation, all patients gave written informed consent. All patients underwent clinical examination including evaluation of diabetes complication status, echocardiography, CMR and blood- and urinary sampling. Information regarding patient medication, history of smoking, coronary artery disease, hypertension and duration of diabetes were collected from the electronical patient journal or reported by the patients themselves. Hypertension was defined as clinical blood pressure $>140 / 90 \mathrm{mmHg}$ after $10 \mathrm{~min}$ of rest or as an active prescription of antihypertensive medication. Coronary artery disease was defined as angiographically verified coronary stenosis, previous myocardial infarction/percutaneous coronary intervention/coronary artery bypass graft or ischemic lesions on late gadolinium enhancement (LGE) CMR. Albuminuria was defined as a urinary albumin/creatinine ratio (UACR) $>30 \mathrm{mg} / \mathrm{g}$ and retinopathy was evaluated from the patients' latest fundus photography, routinely performed in the diabetes outpatient clinic. Autonomic nervous function was evaluated using orthostatic blood pressure measurements and beatto-beat variation. Autonomic neuropathy was diagnosed in patients with a decrease of $25 \mathrm{mmHg}$ or more in the orthostatic systolic blood pressure measurement [11] or with beat-to-beat variation $<4$ beats/min [12]. Peripheral neuropathy was evaluated from the patient's latest chiropodist report and diagnosed in patients whose report indicated signs of sensory nerve damage, patients with typical symptoms of peripheral neuropathy and in male patients with erectile dysfunction. Patients were stratified as receiving mono-, dual- or combination therapy based on their anti-diabetes medication (one, two or three or more anti-diabetes drugs, respectively).

\section{Echocardiography and CMR protocol}

2D Echocardiography was performed on a GE healthcare Vivid E9 cardiovascular ultrasound system, using a GE Vivid S5 probe. CMR was performed on a $1.5 \mathrm{~T}$ scanner (Siemens Avanto; Erlangen, Germany) with spine- and cardiac coil, electrocardiographic gating and patients in the supine position. Detailed information about image 
acquisition and CMR sequence parameters has previously been published [10]. Left ventricular (LV) diastolic function was evaluated from echocardiography. In the apical four-chamber view, peak E was defined as the highest early mitral inflow velocity measured by pulsewave Doppler. Septal and lateral mitral annular velocity $\left(\mathrm{e}^{*}\right)$ were measured using tissue Doppler. E/e* was calculated as the mean of septal and lateral $\mathrm{e}^{*}$ values. When taken individually, $\mathrm{E} / \mathrm{e}^{*}$ has shown the best correlation with invasive measurements of elevated LV filling pressure [13]. Left atrial (LA) structure and LV structure and systolic function were evaluated with CMR. Myocardial perfusion was obtained from 3 short-axis slices (basal, mid-ventricular and apical level) during rest and pharmacological stress (adenosine infusion at a dose of $140 \mu \mathrm{g} /$ $\mathrm{kg} / \mathrm{min}$ for $3 \mathrm{~min}$ ) using a saturation recovery pulse sequence with spoiled gradient echo readout. A contrast dose of $0.075 \mathrm{mg} / \mathrm{kg}$ of gadobutrol (Gadovist ${ }^{\circledR}$, Bayer AG, Germany) was administered at a rate of $5 \mathrm{ml} / \mathrm{s}$ followed by $20 \mathrm{ml}$ of saline for both rest and stress perfusion scans. $\mathrm{T}_{1}$ maps were acquired at similar positions as the perfusion sequences, using a breath-held Shortened Modified Look-Locker Inversion (ShMOLLI) recovery sequence. Native $T_{1}$ mapping was performed prior to the stress perfusion scan; post-contrast $T_{1}$ mapping was performed $10 \mathrm{~min}$ after contrast injection and just before the rest perfusion scan. LGE images were acquired using a phase sensitive inversion recovery reconstruction sequence. LGE images were acquired from the entire LV short axis stack and from the two-, three- and four-chamber views LGE lesions were considered positive if present in 2 or more views.

\section{CMR data analysis}

CMR scans were analyzed with $\mathrm{cmr} 42^{\circledR}$ (Circle Cardiovascular Imaging Inc., Calgary Canada, v. 5.5.1). LV ejection fraction (LVEF), LV end-diastolic volume (EDV), LV end-systolic volume (ESV), LV stroke volume (SV), LV ejection fraction (LVEF), LV mass and LA max volume were analyzed as previously described [14]. Quantification of myocardial blood flow was performed for the midslice perfusion data using an in-house tool developed in MATLAB 2015b (MathWorks, Nattick, MA, USA). Perfusion images were segmented based on the American Heart Association 16-segment model [15] and additional regions were drawn in the LV blood pool in both the perfusion images and $T_{1}$ map. The non-linear response of signal intensity to contrast agent concentration was corrected for based on the baseline signal intensity and $\mathrm{T}_{1}$ data [16]. Data were cropped to the end of the firstpass and Fermi-constrained deconvolution [17] was performed to yield segmental myocardial blood flow (MBF) estimates. Myocardial extracellular volume fraction
(ECV), a variable shown to correlate well with diffuse myocardial fibrosis [18], was calculated from native and postcontrast myocardial $T_{1}$ times and hematocrit values as previously described [19]. ECV was calculated as the mean value of the 6 midventricular segments and any areas with infarction seen on LGE images were excluded.

\section{Fibroblast growth factor-23}

Patients had blood sampling performed just prior to the CMR scan. Following initial handling, the blood samples were immediately transferred to $1 \mathrm{ml}$ cryotubes and stored at $-80{ }^{\circ} \mathrm{C}$ for future usage. After a single freezethaw cycle, FGF-23 was analyzed on EDTA-plasma samples using a chemiluminescence immunoassay (CLIA) on a fully automated chemiluminescence analyzer, the Liaison XL (Diasorin, Saluggia, Italy).

\section{Statistical analysis}

Normally distributed continuous variables are expressed as mean $\pm \mathrm{SD}$ and categorical variables as percentages. Skewed variables are expressed as median and interquartile range (IQR). Depending on the distribution, continuous variables were compared using an unpaired two-tailed student's t-test or Mann-Whitney U test, and categorical variables were compared using the $x^{2}$ test or Fisher's exact test, as appropriate. The general linear model was used for analysis of explanatory variables. Distribution of FGF-23 was skewed and logarithmically transformed for linear correlation. A two-tailed P-value $<0.05$ was considered statistically significant. Statistical calculations were made in SAS Enterprise Guide v. 7.15 (SAS Institute inc., Cary, NC, USA).

\section{Results}

In total, 273 patients with available FGF-23 measurements were included in the original study cohort. Twenty-seven patients with eGFR $<60 \mathrm{ml} / \mathrm{min} / 1.73 \mathrm{~m}^{2}$ were excluded, leaving 246 patients in the final study cohort. Myocardial perfusion was measured in 183 of the 246 patients. In the entire cohort, FGF-23 ranged from 18.9 to $219.4 \mathrm{ng} / \mathrm{L}$ with a median level of 74 (IQR 58-91) $\mathrm{ng} / \mathrm{L}$.

Clinical characteristics of patients with FGF-23 below and above the median are presented in Table 1. Peripheral neuropathy and hypertension were more prevalent in patients with FGF-23 above the median. Angiotensin converting enzyme inhibitors/angiotensin II-receptor blockers (ACE-i/ARB) were more frequently used in patients above the median whereas patients with FGF23 below the median had higher usage of glucagonlike peptide 1 (GLP-1) analogues than did patients above the median. Levels of biomarkers associated with cardiac remodeling and cardiac myocyte damage 
Table 1 Clinical characteristics of patients with FGF-23 below and above the median

\begin{tabular}{|c|c|c|c|}
\hline & \multicolumn{2}{|c|}{ Fibroblast growth factor- 23} & \multirow[t]{2}{*}{ P-value } \\
\hline & Below the median & Above the median & \\
\hline Age (years) & $58 \pm 11$ & $59 \pm 10$ & 0.28 \\
\hline Male sex & $84(68)$ & $89(72)$ & 0.49 \\
\hline $\mathrm{BMI}\left(\mathrm{kg} / \mathrm{m}^{2}\right)$ & $30.7 \pm 4.7$ & $31.8 \pm 4.4$ & 0.06 \\
\hline Duration of diabetes (years) & $12 \pm 8$ & $13 \pm 8$ & 0.14 \\
\hline Albuminuria & $37(30)$ & $51(41)$ & 0.08 \\
\hline Retinopathy & $39(32)$ & $32(26)$ & 0.32 \\
\hline Autonomic neuropathy & $27(22)$ & $36(29)$ & 0.19 \\
\hline Peripheral neuropathy & $43(35)$ & $60(49)$ & 0.03 \\
\hline Clinical SBP (mmHg) & $136 \pm 15$ & $139 \pm 18$ & 0.12 \\
\hline Resting HR (bpm) & $72 \pm 13$ & $72 \pm 11$ & 0.94 \\
\hline Coronary artery disease & $18(15)$ & $22(18)$ & 0.49 \\
\hline Hypertension & $72(59)$ & $97(79)$ & $<0.001$ \\
\hline Active or former smoking & $81(66)$ & $85(69)$ & 0.53 \\
\hline $\mathrm{HbA1c}(\%[\mathrm{mmol} / \mathrm{mol}])$ & $7.8 \pm 1.4(62 \pm 15)$ & $7.9 \pm 1.3(63 \pm 14)$ & 0.56 \\
\hline $\operatorname{eGFR}\left(\mathrm{ml} / \mathrm{min} / 1.73 \mathrm{~m}^{2}\right)$ & $85 \pm 5$ & $82 \pm 10$ & 0.002 \\
\hline LDL cholesterol (mmol/L) & $2.1 \pm 0.9$ & $1.9 \pm 0.8$ & 0.06 \\
\hline HDL cholesterol (mmol/L) & $1.2 \pm 0.4$ & $1.2 \pm 0.3$ & 0.31 \\
\hline Total cholesterol (mmol/L) & $4.4 \pm 1.2$ & $4.2 \pm 0.9$ & 0.07 \\
\hline $\operatorname{proANP}(\mathrm{pmol} / \mathrm{L})$ & $56(41-97)$ & $59(44-105)$ & 0.45 \\
\hline NT-proBNP (pmol/L) & $5.9(5.9-10.8)$ & $5.9(5.9-11.0)$ & 0.71 \\
\hline $\mathrm{Hs}-\mathrm{TnT}(\mathrm{ng} / \mathrm{L})$ & $13(13-15)$ & $13(13-17)$ & 0.38 \\
\hline $\mathrm{Hs}-\mathrm{CRP}$ (mg/L) & $2.0(1.0-4-6)$ & $2.3(1.1-4.3)$ & 0.72 \\
\hline Urine ACR (mg/mmol) & $16(8-42)$ & $18(8-60)$ & 0.23 \\
\hline \multicolumn{4}{|l|}{ Medication } \\
\hline ACE inhibitor/ARB & $80(65)$ & $98(80)$ & 0.01 \\
\hline Statins & $79(64)$ & $87(71)$ & 0.28 \\
\hline SGLT-2 inhibitor & $43(35)$ & $39(32)$ & 0.59 \\
\hline GLP-1 analogue & $54(44)$ & $33(27)$ & 0.005 \\
\hline Insulin & $77(63)$ & $69(56)$ & 0.30 \\
\hline Monotherapy & $22(18)$ & $14(11)$ & 0.21 \\
\hline Dual therapy & $45(47)$ & $46(37)$ & 0.89 \\
\hline Combination therapy & $54(44)$ & $62(50)$ & 0.31 \\
\hline
\end{tabular}

Data presented as mean $\pm S D$, median (Q1-Q3) or as $n$ (\%). ACR albumin creatinine ratio, ARB angiotensin receptor blocker, BMI body mass index, eGFR estimated glomerular filtration rate, GLP-1 glucagon like peptide 1, HR heart rate, $H s$-CRP high sensitivity C-reactive protein, $H s$-TnT high sensitivity troponin T, NT-proBNP $\mathrm{N}$-terminal brain natriuretic peptide, proANP atrial natriuretic peptide, SBP systolic blood pressure, SGLT-2 sodium-glucose cotransporter 2. Significant differences indicated in bold.

(proANP, proBNP, hs-TnT and hs-CRP) did not differ between patients with FGF-23 below and above the median. When directly compared, FGF-23 levels were lower in patients treated with GLP-1 analogues than in those who were not treated with GLP-1 analogues (71 (57-86) vs. 80 (60-98) ng/L, $\mathrm{P}=0.01$ ) (Fig. 1a) and in patients without signs of peripheral neuropathy compared to those with peripheral neuropathy (70 (57-85) vs. 80 (57-97) ng/L, $\mathrm{P}=0.03$ ) (Fig. 1b). FGF-23 in relation to different combinations of anti-diabetes medication is presented in Table 2.
FGF-23 was significantly lower in patients treated with both GLP-1 analogues and insulin only or as combination therapy. Treatment with sodium-glucose cotransporter 2 (SGLT-2) inhibitors as monotherapy or in combination with GLP-1 analogues or insulin were not associated with any significant changes in FGF-23 concentrations. Table 3 shows cardiac structure, function and perfusion in patients with FGF-23 below and above the median. Patients with FGF-23 above the median had higher LV mass $(143 \pm 40$ vs. $138 \pm 36 \mathrm{~g}, \mathrm{P}=0.04)$ and average $\mathrm{E} / \mathrm{e}^{*}$ $(8.5 \pm 3.2$ vs. $7.6 \pm 2.7, \mathrm{P}=0.04)$ as well as lower $\mathrm{MBF}$ 

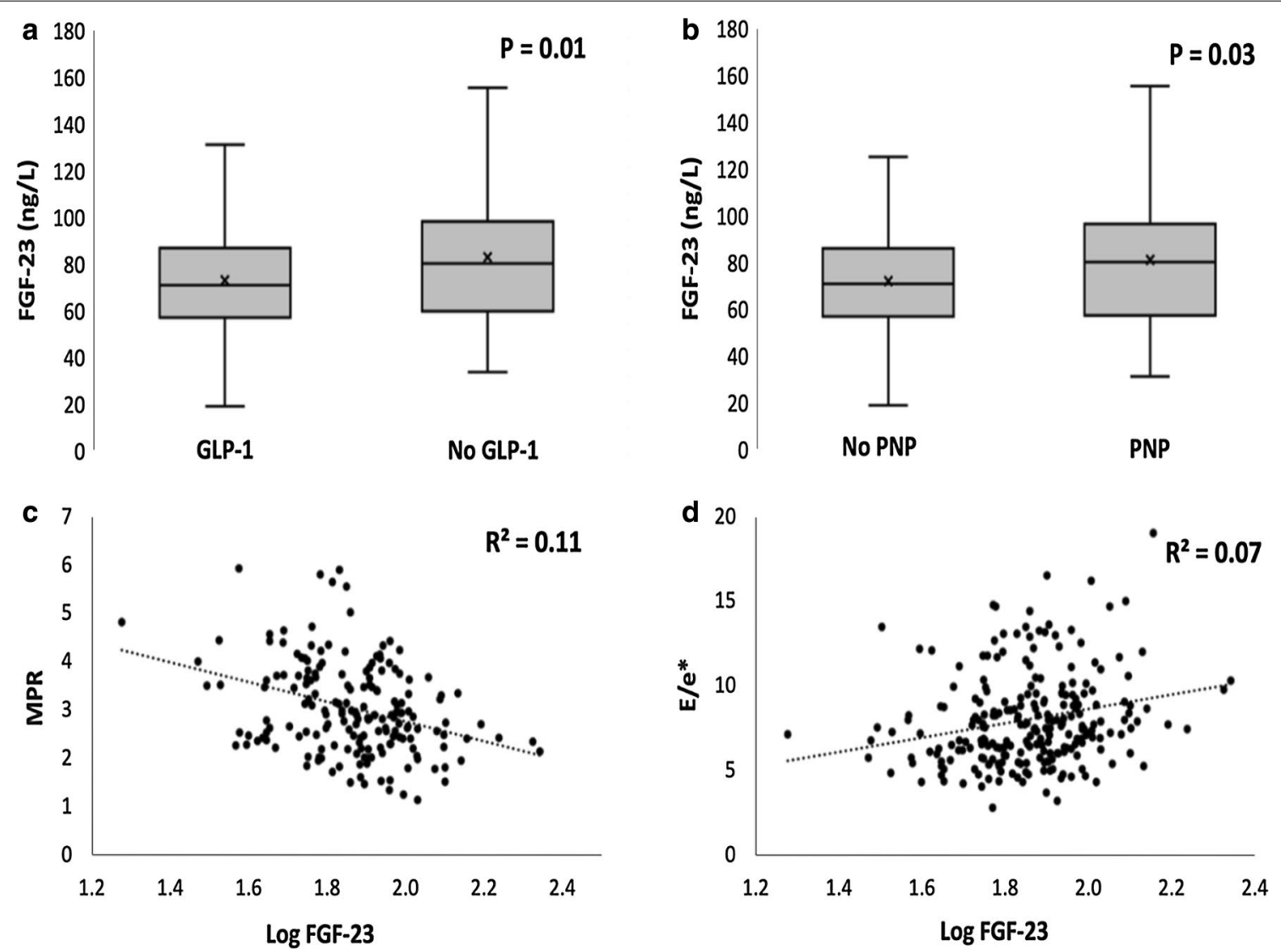

Fig. 1 FGF-23 in patients receiving treatment with GLP-1 analogues alone or in combination with other anti-diabetes medication compared to those who did not receive treatment with GLP-1 analogues (a). FGF-23 in patients with and without peripheral neuropathy (b). Correlation between FGF-23 and myocardial perfusion reserve (MPR) (c) and FGF-23 and E/e* as a measure of cardiac diastolic function (d)

Table 2 Relations between FGF-23 concentrations and different combinations of anti-diabetes therapy

\begin{tabular}{llll}
\hline & Yes & No & P-value \\
\hline SGLT-2 inhibitor only $(n=27)$ & $71(61-94)$ & $75(58-91)$ & 0.89 \\
GLP-1 analogue only $(n=20)$ & $68(55-87)$ & $81(60-98)$ & $\mathbf{0 . 0 4 *}$ \\
SGLT-2 inhibitor+ GLP-1 analogue $(n=16)$ & $74(57-91)$ & $74(61-92)$ & 0.86 \\
Insulin only $(n=67)$ & $68(55-86)$ & $75(60-94)$ & $\mathbf{0 . 0 3}$ \\
Insulin + SGLT-2 inhibitor $(n=28)$ & $75(62-90)$ & $74(57-91)$ & 0.62 \\
Insulin + GLP-1 analogue $(n=40)$ & $72(58-88)$ & $83(60-99)$ & $\mathbf{0 . 0 4}$ \\
Insulin + SGLT-2 inhibitor+ GLP-1 analogue $(n=11)$ & $74(58-93)$ & $75(58-91)$ & 0.76 \\
\hline
\end{tabular}

Data presented as median (Q1-Q3). GLP-1 glucagon like peptide-1, SGLT-2 sodium-glucose cotransporter 2. Significant differences indicated in bold.

during stress $(2.3 \pm 0.9$ vs. $2.7 \pm 0.9 \mathrm{ml} / \mathrm{min} / \mathrm{g}, \mathrm{P}=0.001)$ and lower myocardial perfusion reserve (MPR) $(2.7 \pm 0.8$ vs. $3.3 \pm 1.1, \mathrm{P}<0.001)$ compared with patients with FGF23 below the median. LV mass remained significantly different after indexing to body surface area. We found no differences in LVEF, EDV, ESV, SV, LA max volume, rest MBF or ECV between patients with FGF-23 below or above the median.
In a linear model, increasing FGF-23 was associated with decreased MPR $\left(\mathrm{R}^{2}=0.11, \mathrm{P}<0.001\right)$ (Fig. 1c), increased $E / \mathrm{e}^{*}$ as a measure of cardiac diastolic function $\left(R^{2}=0.07, P=0.001\right.$ ) (Fig. $1 d$ ) and increased urinary albumin creatinine ratio $\left(R^{2}=0.05, P=0.02\right)$. MPR and $\mathrm{E} / \mathrm{e}^{*}$ remained significantly associated with FGF-23 when the model was adjusted for age, sex, eGFR and known hypertension $(\mathrm{P}<0.01$ for both), whereas UACR lost its 
Table 3 Relations between median levels of FGF23 and measurements of cardiac structure, function and perfusion

\begin{tabular}{|c|c|c|c|}
\hline & \multicolumn{2}{|c|}{ Fibroblast growth factor-23 } & \multirow[t]{2}{*}{ P-value } \\
\hline & Below the median & Above the median & \\
\hline LVEF (\%) & $63 \pm 8$ & $63 \pm 7$ & 0.92 \\
\hline $\operatorname{EDV}(\mathrm{ml})$ & $153 \pm 35$ & $154 \pm 37$ & 0.91 \\
\hline EDV index $\left(\mathrm{ml} / \mathrm{m}^{2}\right)$ & $72 \pm 13$ & $70 \pm 15$ & 0.29 \\
\hline ESV $(m l)$ & $58 \pm 22$ & $59 \pm 24$ & 0.75 \\
\hline ESV index $\left(\mathrm{ml} / \mathrm{m}^{2}\right)$ & $27 \pm 9$ & $27 \pm 10$ & 0.78 \\
\hline SV $(\mathrm{ml})$ & $95 \pm 21$ & $95 \pm 20$ & 0.89 \\
\hline LV mass $(\mathrm{g})$ & $138 \pm 36$ & $143 \pm 40$ & 0.04 \\
\hline $\begin{array}{l}\text { LV mass index (g/ } \\
\mathrm{m}^{2} \text { ) }\end{array}$ & $62 \pm 13$ & $66 \pm 16$ & 0.03 \\
\hline LA volume (ml) & $91 \pm 25$ & $97 \pm 27$ & 0.07 \\
\hline $\begin{array}{l}\text { LA volume index } \\
\left(\mathrm{ml} / \mathrm{m}^{2}\right)\end{array}$ & $41 \pm 11$ & $44 \pm 11$ & 0.10 \\
\hline $\begin{array}{l}\text { Rest MBF (ml/ } \\
\mathrm{min} / \mathrm{g})\end{array}$ & $0.81 \pm 0.19$ & $0.83 \pm 0.18$ & 0.69 \\
\hline $\begin{array}{l}\text { Stress MBF (ml/ } \\
\mathrm{min} / \mathrm{g})\end{array}$ & $2.7 \pm 0.9$ & $2.3 \pm 0.9$ & 0.001 \\
\hline MPR & $3.3 \pm 1.1$ & $2.7 \pm 0.8$ & $<0.001$ \\
\hline Average E/e* & $7.6 \pm 2.7$ & $8.5 \pm 3.2$ & 0.04 \\
\hline $\begin{array}{l}\text { Extracellular vol- } \\
\text { ume (\%) }\end{array}$ & $27.8 \pm 3.5$ & $28.6 \pm 3.2$ & 0.51 \\
\hline
\end{tabular}

Data presented as mean $\pm S D$. $L V E F$ left ventricular ejection fraction, $E D V$ enddiastolic volume, ESV end-systolic volume, SV stroke volume, LA left atrial, MBF myocardial blood flow, MPR myocardial perfusion reserve. Significant differences indicated in bold.

significance after adjustment. LV mass was not significantly associated with FGF-23 in a linear model.

\section{Discussion}

An independent relationship between increased circulating levels of FGF-23, incident heart failure and cardiovascular mortality has previously been described in large community-based studies $[5,6]$ and, recently, a similar relationship was confirmed in a larger cohort of patients with type 2 diabetes [9]. It has not previously been systematically investigated, whether increased concentrations of FGF-23 in patients with type 2 diabetes are associated with changes in cardiac function and morphology, as a possible mechanistic explanation for the increased prevalence of cardiovascular events seen in this patient group. In this study, we examined a cohort of patients with type 2 diabetes using echocardiography and quantitative cardiac magnetic resonance imaging, and found that increased levels of FGF-23 were associated with reduced MPR, caused by a decrease in maximal MBF during pharmacological stress, and signs of impaired diastolic function.

\section{FGF-23 and myocardial perfusion}

In the past decades, there has been an emerging interest in diabetic cardiomyopathy and non-ischemic heart failure in patients with type 2 diabetes, and a link between myocardial microvascular disease and cardiac function has previously been demonstrated and suggested as an underlying mechanism of diabetic cardiomyopathy $[10$, 14, 20]. We found that increasing levels of FGF-23 were associated with a decrease in MPR due to impaired perfusion during vasodilator-induced stress, further supporting the theory that microvascular disease plays an important role in the pathogenesis of cardiovascular disease and heart failure in patients with type 2 diabetes, as increased levels of FGF-23 has also been associated with an increased risk of major adverse cardiovascular events including incident heart failure in this group of patients [9]. We used adenosine as a vasodilator substance, which primarily induces endothelium-independent vasodilation by acting directly on the vascular smooth muscle cells $\mathrm{A}_{2}$ receptors [21]. An independent continuous relationship between increased FGF-23 and impaired endothelial-dependent as well as endothelial-independent vasodilation have previously been reported in a large community-based study of subjects with normal renal function [22]. Our data support a similar relation between FGF-23 and vascular dysfunction in patients with type 2 diabetes, however, whether the effect of FGF23 on the vasculature is through alterations in coronary microvascular function, promotion of vascular atherosclerotic calcification, or through physiological modifications in other steps of the vasodilatory process cannot be concluded from the present study. Reduced MPR-in the absence of obstructive coronary artery disease or other cardiovascular risk factors-is associated with heart failure with preserved systolic function [23], and, in the present cohort, we have previously demonstrated that both reduced stress MBF [14] and overall MPR [10] are associated with impaired diastolic function in patients with type 2 diabetes.

\section{FGF-23, LV mass and diastolic function}

In rodents and in-vitro studies, FGF-23 has been demonstrated to directly influence cardiomyocytes and induce LV hypertrophy [24], one of the key characteristic of diabetic cardiomyopathy [25]. In our study, we found that LV mass was generally higher in our group of patients with FGF-23 above the median but we were not able to demonstrate a significant association between LV mass and FGF-23 on a continuous scale. This contrasts the findings of Mirza et al. [26] who showed an association between elevated FGF-23 and LV mass in a large cohort of patients examined with echocardiography. In their entire cohort, 
Mirza et al. found a relatively weak association between FGF-23 and LV mass which may have been mainly driven by patients with eGFR $<60 \mathrm{ml} / \mathrm{min} / 1.73 \mathrm{~m}^{2}$, as they found the strongest association between FGF-23 and LV mass in this patient subgroup. We excluded patients with eGFR $<60 \mathrm{ml} / \mathrm{min} / 1.73 \mathrm{~m}^{2}$ which may explain the discrepancy of the results, and why we were unable to demonstrate a significant association between the two variables on a continuous scale. In addition, we found that increasing levels of FGF-23 were associated with echocardiographic signs of impaired diastolic function. In diabetic cardiomyopathy, LV diastolic dysfunction has been suggested as the earliest functional change detectable and is almost always present prior to signs of LV systolic dysfunction [27]. Hypertension, ageing and diabetes are all associated with an increased risk of developing diastolic dysfunction [28-30], and recently it has been shown that higher glycemic variability may be associated with LV diastolic dysfunction independent of $\mathrm{HbA1c}$ [31]. Recent studies have shown, that treatment with SGLT-2 inhibitors dapagliflozin [32] or canagliflozin [33] can improve LV diastolic function in patients with type 2 diabetes, and that SGLT-2 inhibitors may play a future role in prevention and treatment of cardiovascular disease in patients with type 2 diabetes.

\section{FGF-23 and anti-diabetes therapy}

In our study, we found no association between FGF23 and treatment with SGLT-2 inhibitors, suggesting that the beneficial effect of SGLT-2 inhibitors on LV diastolic function may be through pathways independent of FGF-23. Insulin secretion, and increased plasma concentrations of insulin, is suggested to inhibit the formation of FGF-23 [34], which may explain why we found lower levels of FGF-23 in our patients treated with insulin. Furthermore, treatment with GLP-1 analogues alone and in combination with insulin were also associated with lower levels of circulating FGF23. In the LEADER trial [35], treatment with GLP-1 analogues had a positive effect on a composite cardiovascular outcome consisting of cardiovascular death, nonfatal myocardial infarction and nonfatal stroke. The beneficial effect was evident in both patients with and without chronic kidney disease but did seem to be numerically greater in patients with eGFR $<60 \mathrm{ml} /$ $\min / 1.73 \mathrm{~m}^{2}$, who should also be expected to have the highest levels of circulating FGF-23. In patients with gestational diabetes, FGF-23 may be a promising indicator of subclinical arteriosclerosis [36], and FGF-23 has previously been shown to be positively correlated with the development of coronary atherosclerosis [37]. The anti-atherosclerotic effect of GLP-1 analogues has been suggested as an explanation for the reduction in cardiovascular morbidity and mortality associated with GLP-1 therapy [38], whereas very little data exists on how GLP-1 therapy affects the myocardial microcirculation. One small study $(n=24)$ of patients with type 2 diabetes and no history of coronary artery disease, treated for 10 weeks with the GLP-1 analogue Liraglutide, found no improvements in coronary flow reserve [39]. However, this study used transthoracic Doppler echocardiography to measure coronary flow reserve, limiting the sensitivity for detecting changes in myocardial microvascular function, especially in the relatively small sample size. In addition, the short follow-up period of only 10 weeks may have been insufficient for demonstrating a beneficial effect of GLP-1 therapy on coronary flow reserve. Therefore, to further investigate this topic, larger prospective studies with a longer follow-up period using a more sensitive measure for myocardial microvascular function are warranted. The observational design of our study precludes us from commenting on causality, however, with the apparent correlation between FGF-23 concentrations and treatment with GLP-1 analogues demonstrated in the present study, it would be of interest for future studies to investigate how GLP-1 therapy affects circulating levels of FGF-23 and its relation to cardiovascular outcome in a longitudinal setup.

\section{Limitations}

Our study has some limitations that should be mentioned. The observational design of our study prohibits us from concluding on causality and, as such, our findings are only speculative and should be confirmed in prospective longitudinal studies before any definite conclusions can be made. We did not perform coronary angiography to exclude coronary artery disease and silent ischemia as this would have been both logistically difficult and ethically inappropriate in our population of asymptomatic patients. The stress perfusion CMR scan would have detected any significant ischemia, and as such we do not believe undetected coronary artery disease to have had an important impact on our findings. However, any non-significant coronary artery stenosis or an artery system with balanced ischemia could be a confounding factor as these would not necessarily be revealed from the CMR stress perfusion scan. We did not measure $1,25(\mathrm{OH})_{2}$-vitamin $\mathrm{D}_{3}$ or phosphate levels in our study cohort nor did we record information regarding self-administered or prescribed calcium and vitamin D supplements or dietary phosphate intake. As we have not been able to consider these variables in our calculations we cannot exclude these as a confounding factors. 


\section{Conclusions}

In conclusion, increased levels of circulating FGF-23, in patients with type 2 diabetes and normal to mildly impaired kidney function, is associated with impaired cardiac diastolic function and decreased myocardial perfusion reserve, caused by a decrease in maximal myocardial blood flow during pharmacological vasodilator stress. Peripheral neuropathy is associated with higher concentrations of circulating FGF-23, whereas patients treated with GLP-1 analogues or insulin have lower levels of circulating FGF-23. Our results support a relationship between FGF-23 and imaging markers of diabetic cardiomyopathy, and FGF-23 has previously been proposed as a potential predictor of cardiovascular disease in patients with diabetes [40]. These findings warrant for future studies to examine the predictive value of FGF-23 for cardiovascular morbidity and mortality in patients with type 2 diabetes, as FGF-23 may prove to be a useful biomarker for identifying patients at high risk of adverse cardiovascular outcome.

\begin{abstract}
Abbreviations
ACE-i/ARB: Angiotensin converting enzyme inhibitors/angiotensin II-receptor blockers; CAD: Coronary artery disease; CMR: Cardiac magnetic resonance imaging; ECV: Extracellular volume; EDV: End-diastolic volume; eGFR: Estimated glomerular filtration rate; ESV: End-systolic volume; FGF-23: Fibroblast growth factor-23; GLP-1: Glucagon like peptide-1; LA: Left atrium; LGE: Late gadolinium enhancement; LV: Left ventricle; LVEF: LV ejection fraction; MBF: Myocardial blood flow; MPR: Myocardial perfusion reserve; NSR: Næstved/ Slagelse/Ringsted; SGLT-2: Sodium glucose co-transporter-2; UACR: Urinary albumin/creatinine ratio.
\end{abstract}

\section{Acknowledgements}

The authors acknowledge staff in the Departments of Cardiology and Radiology at NSR hospitals for their support in the execution of this study. Special thanks go to cardiac radiographers Anette Ohrt Elingaard-Larsen, Alice Holm Møller, Jakob Engelhardt Riis and Karen Larsen, Department of Radiology, Næstved Hospital, Region Zealand, Denmark, for their expert assistance in performing the CMR scans. The Study Was conducted at the Department of Cardiology and Endocrinology, Slagelse Hospital, Denmark and at the Department of Radiology, Næstved Hospital, Denmark

\section{Authors' contributions \\ MHS collected and researched data and wrote the manuscript. ASB collected data and reviewed and edited the manuscript. SP reviewed and edited the manuscript. DAB and NRJ researched the data and reviewed and edited the. PLM and PG designed the study and reviewed and edited the manuscript. MHS and PG are the guarantors of this work and, as such, had full access to all data in the study and takes responsibility for the integrity of the data and the accuracy of the data analysis. All authors read and approved the final manuscript.}

\section{Funding}

This work was supported by the local research committee at NSR hospitals, the regional research committee of Region Zealand [13-000849] and the Danish Heart Foundation [16-R107-A6819-22020].

\section{Availability of data and materials}

The datasets analysed during the current study are not publicly available due consideration of intellectual property, due to continuing analyses by the study investigators but are available from the corresponding author on reasonable request.

\section{Ethics approval and consent to participate}

The local ethics committee of Region Zealand (SJ-490) approved the study protocol; the study complied with the declaration of Helsinki; all patients provided both oral and written informed consent before enrolment; the full description of the study design has been registered on clinicaltrials.gov (NCT02684331).

\section{Consent for publication}

Not applicable.

\section{Competing interests}

The authors declare that they have no competing interests.

\section{Author details}

${ }^{1}$ Department of Cardiology and Endocrinology, Slagelse Hospital, Ingemannsvej 32, 4200 Slagelse, Region Zealand, Denmark. ${ }^{2}$ Institute of Regional Health Research, Faculty of Health Sciences, University of Southern Denmark, Odense, Denmark. ${ }^{3}$ Department of Clinical Biochemistry, Rigshospitalet, Glostrup, Capital Region of Denmark, Denmark. ${ }^{4}$ Department of Medical Physics and Engineering, Leeds Teaching Hospitals NHS Trust, Leeds, UK. ${ }^{5}$ Leeds Institute of Cardiovascular and Metabolic Medicine, University of Leeds, Leeds, UK. ${ }^{6}$ Department of Cardiology, Copenhagen University Hospital Herlev-Gentofte, Hellerup, Capital Region of Denmark, Denmark. ${ }^{7}$ Department of Clinical Medicine, University of Copenhagen, Copenhagen, Denmark.

Received: 29 July 2020 Accepted: 23 September 2020

Published online: 30 September 2020

\section{References}

1. Kannel WB, Hjortland M, Castelli WP. Role of diabetes in congestive heart failure: the Framingham study. Am J Cardiol. 1974;34:29-34.

2. Taylor KS, Heneghan CJ, Farmer AJ, Fuller AM, Adler Al, Aronson JK, et al. All-cause and cardiovascular mortality in middle-aged people with type 2 diabetes compared with people without diabetes in a large U.K. primary care database. Diabetes Care. 2013;36:2366-71.

3. Shimada T, Hasegawa H, Yamazaki Y, Muto T, Hino R, Takeuchi Y, et al. FGF-23 is a potent regulator of vitamin D metabolism and phosphate homeostasis. J Bone Miner Res. 2004;19:429-35.

4. Larsson T, Nisbeth U, Ljunggren Ö, Jüppner H, Jonsson KB. Circulating concentration of FGF-23 increases as renal function declines in patients with chronic kidney disease, but does not change in response to variation in phosphate intake in healthy volunteers. Kidney Int. 2003;64:2272-9.

5. Ix JH, Katz R, Kestenbaum BR, De Boer IH, Chonchol M, Mukamal KJ, et al. Fibroblast growth factor-23 and death, heart failure, and cardiovascular events in community-living individuals: CHS (Cardiovascular Health Study). J Am Coll Cardiol. 2012;60:200-7.

6. Marthi A, Donovan K, Haynes R, Wheeler DC, Baigent C, Rooney CM, et al. Fibroblast growth factor-23 and risks of cardiovascular and noncardiovascular diseases: a meta-analysis. J Am Soc Nephrol. 2018;29:2000-133.

7. Tuñón J, Fernández-Fernández B, Carda R, Pello AM, Cristóbal C, Tarín N, et al. Circulating fibroblast growth factor-23 plasma levels predict adverse cardiovascular outcomes in patients with diabetes mellitus with coronary artery disease. Diabetes Metab Res Rev. 2016;32:685-93.

8. Bergmark BA, Udell JA, Morrow DA, Cannon CP, Steen DL, Jarolim P, et al. Association of fibroblast growth factor 23 with recurrent cardiovascular events in patients after an acute coronary syndrome A secondary analysis of a randomized clinical trial. JAMA Cardiol. 2018;3:473-80.

9. Yeung $\mathrm{SMH}$, Binnenmars SH, Gant CM, Navis G, Gansevoort RT, Bakker $\mathrm{SJ}$, et al. Fibroblast growth factor 23 and mortality in patients with type 2 diabetes and normal or mildly impaired kidney function. Diabetes Care. 2019;42:2151-3.

10. Sørensen MH, Bojer AS, Broadbent DA, Plein S, Madsen PL, Gæde P. Cardiac perfusion, structure, and function in type 2 diabetes mellitus with and without diabetic complications. Eur Hear J Cardiovasc Imaging. 2020;21:887-95.

11. Hilsted J. Decreased sympathetic vasomotor tone in diabetic orthostatic hypotension. Diabetes. 1979;28:970-3. 
12. Nielsen FS, Rossing P, Bang LE, Svendsen TL, Gall M, Smidt UM. On the mechanisms of blunted nocturnal decline in arterial blood pressure in NIDDM patients with diabetic nephropathy. Diabetes. 1995;44:783-9.

13. Nauta JF, Hummel YM, van der Meer P, Lam CSP, Voors AA, van Melle JP. Correlation with invasive left ventricular filling pressures and prognostic relevance of the echocardiographic diastolic parameters used in the 2016 ESC heart failure guidelines and in the 2016 ASE/EACVI recommendations: a systematic review in patients with heart failure and preserved ejection fraction. Eur J Heart Fail. 2018;20:1303-11.

14. Sørensen MH, Bojer AS, Pontoppidan JRN, Broadbent DA, Plein S, Madsen $\mathrm{PL}$, et al. Reduced myocardial perfusion reserve in type 2 diabetes is caused by increased perfusion at rest and decreased maximal perfusion during stress. Diabetes Care. 2020;43:1285-92.

15. Cerqueira MD, Weissman NJ, Dilsizian V, Jacobs AK, Kaul S, Laskey WK, et al. Standardized myocardial segmentation and nomenclature for tomographic imaging of the heart. A statement for healthcare professionals from the Cardiac Imaging Committee of the Council on Clinical Cardiology of the American Heart Association. Circulation. 2002;105:539-42.

16. Biglands J, Magee D, Boyle R, Larghat A, Plein S, Radjenović A. Evaluation of the effect of myocardial segmentation errors on myocardial blood flow estimates from DCE-MRI. Phys Med Biol. 2011;56:2423-43.

17. Jerosch-Herold M, Wilke N, Stillman AE. Magnetic resonance quantification of myocardial perfusion with a Fermi function model for constrained deconvolution. Med Phys. 1998;25:73-84.

18. Wong TC, Piehler KM, Kang IA, Kadakkal A, Kellman P, Schwartzman DS, et al. Myocardial extracellular volume fraction quantified by cardiovascular magnetic resonance is increased in diabetes and associated with mortality and incident heart failure admission. Eur Heart J. 2014;35:657-64.

19. Iles L, Pfluger H, Phrommintikul A, Cherayath J, Aksit P, Gupta SN, et al. Evaluation of Diffuse Myocardial Fibrosis in Heart Failure With Cardiac Magnetic Resonance Contrast-Enhanced T1 Mapping. J Am Coll Cardiol. 2008:52:1574-80.

20. Larghat AM, Swoboda PP, Biglands JD, Kearney MT, Greenwood JP, Plein S. Themicrovascular effects of insulin resistance and diabetes on cardiac structure, function, and perfusion: a cardiovascular magnetic resonance study. Eur Heart J Cardiovasc Imaging. 2014;15:1368-76.

21. Lanza GA, Camici PG, Galiuto L, Niccoli G, Pizzi C, Di Monaco A, et al. Methods to investigate coronary microvascular function in clinical practice. J Cardiovasc Med. 2013;14:1-18

22. Mirza MAl, Larsson A, Lind L, Larsson TE. Circulating fibroblast growth factor-23 is associated with vascular dysfunction in the community. Atherosclerosis. 2009;205:385-90.

23. Srivaratharajah K, Coutinho T, Dekemp R, Liu P, Haddad H, Stadnick E, et al. Reduced myocardial flow in heart failure patients with preserved ejection fraction. Circ Hear Fail. 2016;9:1-9.

24. Faul C, Keane MG, Wolf M, Faul C, Amaral AP, Oskouei B, et al. FGF23 induces left ventricular hypertrophy. J Clin Invest. 2011;121:4393-408.

25. Rubler S, Dlugash J, Yuceoglu YZ, Kumral T, Branwood AW, Grishman A. New type of cardiomyopathy associated with diabetic glomerulosclerosis. Am J Cardiol. 1972;30:595-602.

26. Mirza MAl, Larsson A, Melhus H, Lind L, Larsson TE. Serum intact FGF23 associate with left ventricular mass, hypertrophy and geometry in an elderly population. Atherosclerosis. 2009;207:546-51.
27. Murarka S, Movahed MR. Diabetic cardiomyopathy. J Card Fail. 2010;16:971-7.

28. Mahoney DW, Jacobsen SJ, Rodeheffer RJ, Burnett JC Jr, Redfield MM, Bailey KR. Burden of systolic and diastolic ventricular dysfunction in the community. JAMA. 2003;289:194.

29. Nishimura RA, Tajik AJ. Evaluation of diastolic filling of left ventricle in health and disease: Doppler echocardiography is the clinician's Rosetta Stone. J Am Coll Cardiol. 1997;30:8-18.

30. Fontes-Carvalho R, Ladeiras-Lopes R, Bettencourt P, Leite-Moreira A, Azevedo A. Diastolic dysfunction in the diabetic continuum: Association with insulin resistance, metabolic syndrome and type 2 diabetes. Cardiovasc Diabetol. 2015;14:1-9.

31. Yokota S, Tanaka H, Mochizuki Y, Soga F, Yamashita K, Tanaka Y, et al. Association of glycemic variability with left ventricular diastolic function in type 2 diabetes mellitus. Cardiovasc Diabetol. 2019;18:1-8.

32. Soga F, Tanaka H, Tatsumi K, Mochizuki Y, Sano H, Toki H, et al. Impact of dapagliflozin on left ventricular diastolic function of patients with type 2 diabetic mellitus with chronic heart failure. Cardiovasc Diabetol. 2018;17:1-8.

33. Matsutani $D$, Sakamoto M, Kayama Y, Takeda N, Horiuchi R, Utsunomiya K. Effect of canagliflozin on left ventricular diastolic function in patients with type 2 diabetes. Cardiovasc Diabetol. 2018;17:1-12.

34. Bär L, Feger M, Fajol A, Klotz LO, Zeng S, Lang F, et al. Insulin suppresses the production of fibroblast growth factor 23 (FGF23). Proc Natl Acad Sci USA. 2018:115:5804-9.

35. Mann JFE, Fonseca V, Mosenzon O, Raz I, Goldman B, Idorn T, et al. Effects of liraglutide versus placebo on cardiovascular events in patients with type 2 diabetes mellitus and chronic kidney disease: results from the LEADER trial. Circulation. 2018;138:2908-18.

36. Tuzun D, Oguz A, Aydin MN, Kurutas EB, Ercan O, Sahin M, et al. Is FGF-23 an early indicator of atherosclerosis and cardiac dysfunction in patients with gestational diabetes? Arch Endocrinol Metab. 2018;62:506-13.

37. Akin F, Celik O, Altun I, Ayca B, Diker VO, Satilmis S, et al. Relationship of fibroblast growth factor 23 and fetuin-A to coronary atherosclerosis. J Diabetes Complicat. 2015;29:550-5.

38. Garg V, Verma S, Connelly K. Mechanistic insights regarding the role of SGLT2 inhibitors and GLP1 agonist drugs on cardiovascular disease in diabetes. Prog Cardiovasc Dis. 2019:62:349-57.

39. Faber R, Zander M, Pena A, Michelsen MM, Mygind ND, Prescott E. Effect of the glucagon-like peptide-1 analogue liraglutide on coronary microvascular function in patients with type 2 diabetes - a randomized, single-blinded, cross-over pilot study. Cardiovasc Diabetol. 2015;14:1-11.

40. Berezin AE, Berezin AA. Impaired function of fibroblast growth factor 23 / Klotho protein axis in prediabetes and diabetes mellitus: Promising predictor of cardiovascular risk. Diabetes Metab Syndr Clin Res Rev. 2019;13:2549-56.

\section{Publisher's Note}

Springer Nature remains neutral with regard to jurisdictional claims in published maps and institutional affiliations.

Ready to submit your research? Choose BMC and benefit from

- fast, convenient online submission

- thorough peer review by experienced researchers in your field

- rapid publication on acceptance

- support for research data, including large and complex data types

- gold Open Access which fosters wider collaboration and increased citations

- maximum visibility for your research: over $100 \mathrm{M}$ website views per year

At BMC, research is always in progress.

Learn more biomedcentral.com/submissions 